\title{
A home-made method to remove an SX-Ella Danis stent
}

A 48-year-old man with alcoholic liver cirrhosis, Child-Pugh score A(6), became ill when on a business trip to Copenhagen, Denmark. Massive hematemesis and severe hepatic encephalopathy occurred, and he underwent placement of an SX-Ella Danis covered stent (EllaCS, Hradec Králové, Czech Republic) (॰ Fig. 1, \Fig.2) in a Danish hospital. After stabilization, he was transferred back to Taiwan - where no Ella extractor was available. The stent had now been in position for over 2 weeks. We used a polypectomy snare (Olympus SD-5U/6U-1) ( Fig. 3) and a 50-cm-long tapered overtube (Cliny Inc., Japan) to successfully and smoothly remove the stent ( $\nabla$ Video 1 ).

The SX-Ella Danis covered stent has been reported as useful in patients with acute esophageal variceal bleeding [1]. The Baveno VI Consensus suggested that selfexpanding covered esophageal metal stents may be a safer option than balloon tamponade in cases of refractory esophageal variceal bleeding [2]. According to the recommendation of the Ella-CS company, however, the stent should be removed after 7 days, and removal or repositioning of the SX-Ella Danis stent requires the Ella extractor. For this reason, on occasions when patients receive emergent hemostasis with an Ella-CS stent abroad, then return home to a country where the PEX-Ella extractor is not available, extraction could be a problem.

We present an easy, home-made method for removing a self-expanded metal stent without the original extractor. Our experience could perhaps provide a handy hint for endoscopists who practice in regions where an original extractor cannot be obtained.

Endoscopy_UCTN_Code_TTT_1AO_2AN

\section{Competing interests}

None

The authors

Yu-Jen Chen ${ }^{1}$, Ming-Chih Hou ${ }^{1,2}$

1 Division of Gastroenterology and Hepatology, Department of Medicine, Taipei Veterans General Hospital, Taiwan

2 National Yang-Ming University School of Medicine, Taipei, Taiwan

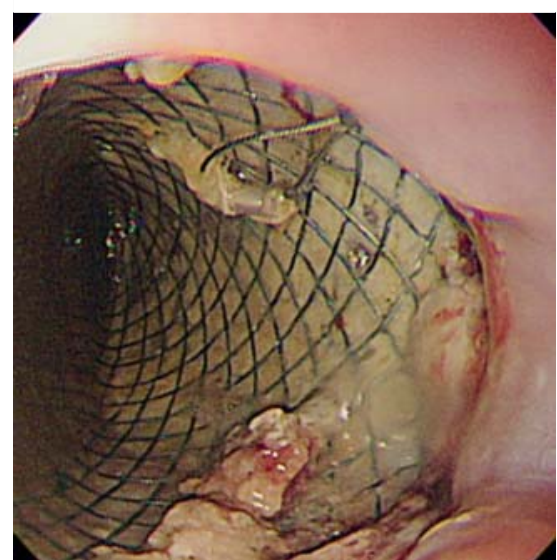

Fig. 1 Esophagogastroduodenoscopy revealed a covered metal stent in the middle part of the esophagus.

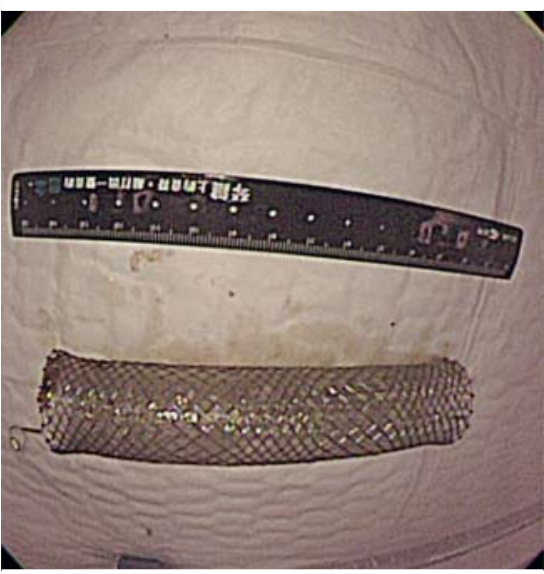

- Fig. 2 The SX-Ella Danis stent expanded after removal from the esophagus.

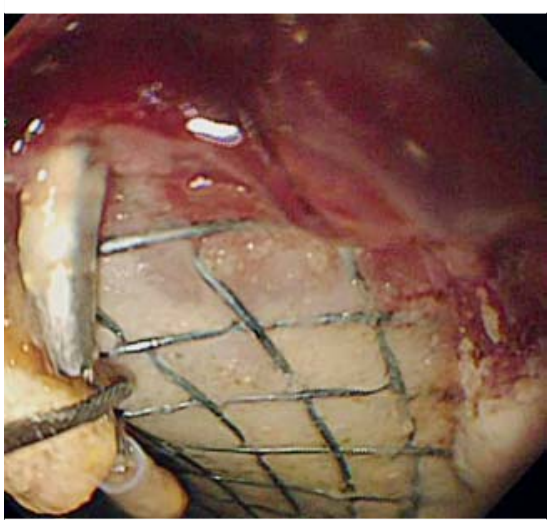

Fig. 3 We used a snare to capture the retrieval loop at the stent tip. able. 


\section{Ming-Chih Hou, MD}

Division of Gastroenterology and

Hepatology, Department of Medicine, Taipei

Veterans General Hospital, No. 201, Sec. 2

Shih-Pai Road, Taipei 112, Taiwan

Fax: +886-2- 28739318

mchou@vghtpe.gov.tw

\section{References}

[1] Hubmann R, Bodlaj G, Czompo M et al. The use of self-expanding metal stents to treat acute esophageal variceal bleeding. Endoscopy 2006; 38: 896-901
2] de Franchis R, Baveno VI Faculty. Expanding consensus in portal hypertension: Report of the Baveno VI Consensus Workshop: Stratifying risk and individualizing care for portal hypertension. J Hepatol 2015; 63: 743-752

Bibliography

DOI https://doi.org/10.1055/a-1046-1785

Published online: 13.12.2019

Endoscopy 2020; 52: E198-E199

(c) Georg Thieme Verlag KG

Stuttgart · New York

ISSN 0013-726X

\section{ENDOSCOPY E-VIDEOS}

https://eref.thieme.de/e-videos

口否回 Endoscopy E-Videos is a free 然故 access online section, reporting 回解: on interesting cases and new techniques in gastroenterological endoscopy. All papers include a high quality video and all contributions are freely accessible online.

This section has its own submission website at

https://mc.manuscriptcentral.com/e-videos 